\title{
Growth, Inequality and Structural Adjustment: An Empirical Interpretation of the S-Curve for Indian Economy
}

\author{
Narain Sinha* \\ Professor of Economics \\ University of Rajasthan \\ Jaipur INDIA
}

- $\quad$ Presently with the Department of Economics, University of Botswana, Gaborone. The work had been initially undertaken under the auspices of Special Assistance Programme in Economics, University of Rajasthan, Jaipur (India). It is a revised version of the paper presented in the Tenth Anniversary of ASPC Conference organized at ANU, Canberra. The author is highly grateful to Raghbendra Jha of the Australian National University, Canberra and R. Tribble for the comments and suggestions on an earlier draft and the participants of the Conference for the comments which have indeed resulted in its improvement. The computational assistance rendered by Sanjeev Kr Jain and Lokendra S Kumawat is duly acknowledged. The author is grateful to for the comments. Usual disclaimers apply.

- E-mail: sinhan@mopipi.ub.bw 


\title{
Growth, Inequality and Structural Adjustment: An Empirical Interpretation of the S-Curve for the Indian Economy
}

\author{
Narain Sinha
}

\begin{abstract}
Extending the Kuznets' hypothesis of economic growth (KHEG) an attempt is made in the present paper to examine its validity for the Indian Economy during the period 1980-81 through 1997-98. The results provide an econometric explanation for the increase in inequality after 1990-91 and seek to defend the strategy of economic development followed in India. The conclusions suggest that the reason for the inequalities lies in the social and political restructuring taking place in the Indian economy. Need therefore is to investigate the social decomposition of the economic inequality.
\end{abstract}

Most developing countries have witnessed a higher rate of growth in the modern industrial sector. This highlights the fact that effect of growth in one sector is crucial to growth in another. Thus, sectoral composition of economic growth changes with time influencing the economic inequality. A change in overall level of economic development, according to the Kuznets' Hypothesis of Economic Growth (KHEG), results in increase/decrease in inequality also. During various stages of development a structural shift of agriculture to manufacture (ATM) or manufacturing to service (MTS) is responsible for the turning points in the Kuznets'-U-process. Theories of growth and distributional change have emphasized the role played by economic shifts from the traditional rural sector to the modern urban sector. A sectoral interdependence of economic activities thus may enhance or retard its direct effect on inequality, for overall inequality is a population weighted average of sectoral inequalities. It will be of interest to look at the relationship between economic development measured in terms of per capita income and economic inequality, because of its wide-ranging implications for poverty reduction and through it for the economic reforms initiated vigorously in most of the developing economies and particularly in India in 1991. It is argued that when the share of secondary sector increases during the second stage, inequality declines due to shifts of ATM thus, an inverted U-curve occurs. Another turning point occurs during the third stage of development, which corresponds to MTS, and thus it becomes an augmented inverted U-curve.

Of late Dutt (1999) has examined the trends in poverty and concluded that in the post-reforms period, rural poverty has remained stagnant whereas the urban poverty has declined. However, according to Ahluwalia (2000) the interstate inequality (measured in 
terms of the Gini coefficient) was fairly stable upto 1986-87 and it started increasing in the late 1980s and continued upto 1997-98. The increase in the Gini coefficient from 0.16 in $1987-88$ to 0.228 in $1997-98$ was substantial. It plummeted subsequently to 0.225 . The overall growth rate of GSDP was $5.24 \%$ during 1980 s, which reportedly rose to 5.94\% during the period 1991-92 to 1997-98. This establishes the fact that there exists a positive correlation between development and Gini coefficient. In the light of these findings, several attempts have been made to explain the rising trend in inequality and the number of persons below poverty line during the last decade. The major objective in the present paper is to provide explanation for an increase in inequality in India during the last two decades, especially after 1990-91. The following section describes the findings of other studies on the empirical relationship between inequality and level of income. In section II, we describe the methodology. Section III presents data description along with our results and discusses their implications. Conclusions are given in section IV.

\section{Review of Literature}

A stylized model describing the relationship between development and distribution was first sketched by Kuznets (1955) and later formalized by Anand and Kanbur (1993). Using an ambitious model, Greenwood and Jovanovic (1990) have shown that income distribution and growth are correlated over time due to financial development. A relationship between a measure of inequality and the level of income to test for consistency of the original Kuznets' hypothesis allows its partial revival. Accordingly, there appears to be a U-curve relationship between development and inequality. Expressing inequality as a polynomial in income marks a complete revival of what has been termed as the Kuznets' process by Anand and Kanbur. Results obtained do validate the correct parabolic shape both for all countries and for developing countries alone but were not statistically significance. However, it may be taken as an evidence of inherent tendencies toward greater inequality when the economic restructuring from low levels of income takes place, hence resulting in an augmented Kuznets’ curve.

The idea that both low-income and high - income economies would have lower inequality was initially advanced by Kuznets (1955), and was re-examined mathematically by Anand and Kanbur (1993). This stylized fact that with the economic development, the income distribution within economy becomes more unequal has attracted various attempts to reexamine it. Only in the later phase of the development, it becomes more equal. This empirical observation is also being seen in the context of modern developing countries - at least the increasing inequality phase- and has acquired the force of economic law - the U hypothesis (Robinson 1976). Ram (1991), Bound and Johnson (1992) and Dawson (1997) have provided evidence in support of an inverted Ushaped pattern for highly developed countries by considering a quadratic specification. Similarly, while testing the Kuznets' hypothesis econometrically, Anand and Kanbur for developing countries, and Fishlow (1995), for all countries (61 in number) and developing countries (42 in number), estimated a parabolic relation between Gini 
Coefficient and income level. The results for developing countries were far from significance statistically. Recently, List and Gallet (1999) and Tribble (1996, 1999) have observed that the Kuznets' inverted U-curve is in fact an S-curve. It has been endorsed in these studies by considering panel data and time series data respectively. The inequality and development have been found to be correlated positively upto a critical level of economic activity. Considering the cubic formulation in per capita income, the observed relationship between inequality and development was neither U- shaped nor inverted U-shaped, it was termed as an S-curve by Tribble (1996). These results thus support the extended Kuznets' hypothesis and may be aptly termed as an augmentation of the inverted U-curve, as the coefficients were significant, though the $\mathrm{R}^{2}$ was very low. It suggests that the Kuznets' inverted U-curve is really an S-curve where the first turning point is associated with transition from agriculture-to-manufacturing (ATM) while the second turning point corresponds to a structural transition from manufacturing-toservice (MTS). The results obtained by Dawson (1997), Bound and Johnson (1992), Fishlow (1995) and others have endorsed a parabolic curve whereas Tribble (1996, 1999) and List and Gallet (1999) confirm a cubic or S-curve instead of inverted U-curve, thus concluding that an economy has achieved the second turning point (i.e., the MTS).

In the context of the Indian economy the period upto 1985 may be termed as the one when agriculture was a leading sector, but subsequently manufacturing sector became prominent. Considering an aggregate inequality measure, Dutt (1999) has observed no significant trend in inequality at the sectoral (rural/urban) level during 1973-91 and 1991-97 period. However, at the national level the inequality seems to have increased as reflected in a positive coefficient in the trend equation. This observation has cast serious doubts on the success of structural adjustment programme and economic reforms in India, and raises the question whether the poor have been benefitted by the economic reforms. In the light of this evidence even the political party who spearheaded the economic reforms mildly in 1985 and vigorously in 1991 has decided to have its reassessment. Critics of economic reforms have argued that the nature of growth resulting from economic liberalization during 1990s may have been less distributionally benign than earlier (Ahluwalia, 2000), and thus conclude that an increase in the inter-state inequality may be due to a common perception that the rich states are getting richer and the poor states are getting 'poorer'. This may not be entirely true, because no Indian state is getting poorer in absolute sense. On the contrary, during the last decade the poorer states are getting richer albeit at a rate, which is lower than that of the richer states $^{1)}$. Recently, Jha (2000) has examined the empirical relationship between economic inequality, poverty and economic growth in the Indian states using the NSS data, and concludes that both inequality and poverty do converge, but inequality acts as a constraint on growth. Rao et al. (1999) have observed a negative relationship between

\footnotetext{
1) In other words, the growth rates of the poor states during the nineties have been lower than their corresponding rates in the eighties (see Tables 1 and 2, Ahluwalia and reproduced in the Appendix). The performance of Madhya Pradesh, Tamil Nadu, Kerala, West Bengal, Gujarat and Maharashtra has been spectacular, whereas that of Rajasthan, Andhra Pradesh and Karnataka is satisfactory. The states Bihar, Uttar Pradesh, Orissa, Haryana and Punjab have not done even satisfactory.
} 
growth and the Gini Coefficient. Although the conventional wisdom suggests that high Gini coefficient accompanies poor growth, a positive correlation between inequality and development in advanced economies like the United States cannot be ruled out, as increasing inequality is strategic to realising economic development.

\section{Methodology}

Sinha et al. (2000) have examined the hypothesis that the Gini Coefficient and PBPL follow a random walk without trend indicating that both follow a random walk, and the RPCI is I (2) during the sample period. This supports the observation that there is much more freedom in the way distribution may change over time (Bourguignon, 1995). Robinson (1976) has derived a relationship between inequality and sectoral composition. In the present paper, besides a cubic the quortic and quintic relationships have been tried between the Gini coefficient and income level ${ }^{2}$.

$$
G_{t}=\alpha+\beta X_{t}+\Phi t+\epsilon_{t}
$$

Where $\mathrm{G}=\mathrm{GINI}$ Coefficient,

$$
\begin{aligned}
& \mathrm{X}=\left[\begin{array}{lll}
\mathrm{y} & \mathrm{y}^{2} & \mathrm{y}^{3}
\end{array}\right] \\
& \mathrm{y}=\text { real per capita income (RPCI), and } \\
& \mathrm{t}=\text { time. }
\end{aligned}
$$

Specifically, if time is dropped then we have

$\mathrm{GINI}_{\mathrm{t}}=\beta_{0}+\beta_{1} \mathrm{y}_{\mathrm{t}}+\beta_{2} \mathrm{y}_{\mathrm{t}}^{2}+\beta_{3} \mathrm{y}_{\mathrm{t}}^{3}+\epsilon_{\mathrm{t}}$

such that

$$
\left|\beta_{1}\right|>\left|\beta_{2}\right|>\left|\beta_{3}\right|
$$

Now there are two cases. First, there is an S-curve or 'augmented inverted U-curve' if $\beta_{1}>0, \beta_{2}<0$, and $\beta_{3}>0$

On the other hand, if $\beta_{1}<0, \beta_{2}>0$, and $\beta_{3}<0$ then it will be an S-curve again but as an augmentation of U-curve. Similar specification would be employed with the persons below poverty line (PBPL) as the dependent variable.

\section{Empirical Results}

For the period 1980-81 through 1997-98, the inter-state inequality measure of Gini Coefficients has been taken from Ahluwalia (2000) and real per capita income from NAS (Table 1A). For the purpose of the present paper, we have first obtained a linear

\footnotetext{
2) Tribble (1999).
} 
trend in Gini Coefficient, people below poverty line (PBPL) and real per capita income (RPCI). Following three equations were estimated ${ }^{2]}$

$$
\begin{array}{ll}
\text { GINI }=0.13041+0.0050743(\text { TIME) } & \mathrm{R}^{2}=0.8675 \\
\text { p-value }(0.000)(0.000) & \mathrm{DW}=0.47 \\
\mathrm{JB}=1.0029(0.606) &
\end{array}
$$

The Cochrane-Orcutt transformation yields the following equation:

$$
\begin{array}{ll}
\text { GINI }=11097+0.0064328(\text { TIME }) & \mathrm{R}^{2}=0.9525 \\
\mathrm{p} \text {-value }(0.000)(0.000) & \mathrm{DW}=2.12
\end{array}
$$

In both of these equations, smaller p-value suggests significant coefficient. The positive and significant trend has been interpreted as an evidence against the economic reforms (Dutt, 1999), but it is not correct as it is accompanied by a positive trend in RPCI also as can be seen in following equation.

$$
\begin{aligned}
& \mathrm{RPCI}=1643.9+75.7059(\mathrm{TIME}) \quad \mathrm{R}^{2}=0.9562 \\
& \text { p-value (0.000) (0.000) DW }=0.53 \\
& \mathrm{JB}=0.69951(0.705)
\end{aligned}
$$

Cochrane-Orcutt transformation with AR (2) yields the following equation

$$
\begin{array}{ll}
\text { RPCI }=1424.8+95.3879(\mathrm{TIME}) & \mathrm{R}^{2}=0.9814 \\
\mathrm{p}-\text { value } \quad(0.004)(0.010) & \mathrm{DW}=1.91 \\
\mathrm{PBPL}=39.2685-0.2097(\mathrm{TIME}) & \mathrm{R}^{2}=0.1022 \\
\mathrm{p}-\text { value }(0.000) \quad(0.338) & \mathrm{DW}=2.36
\end{array}
$$

Both Gini Coefficient and real per capita income display a positive and significant trend, whereas the trend coefficient for poverty ratio is not only negative but also it is far from significance (as indicated by higher p-value).

To validate the S-curve hypothesis, we obtain the following equations

$$
\begin{array}{lcc}
\text { GINI }=1.4983-0.0017(\mathrm{RPCI})+0.7190 \times 10^{-6}(\mathrm{RPCI})^{2}-0.0039 \times 10^{-6}(\mathrm{RPCI})^{3} \\
\begin{array}{lcc}
\mathrm{p} \text {-value }(0.008)(0.012) & (0.012) & (0.015) \\
\mathrm{JB}=0.36068(0.835) & \mathrm{n}=17
\end{array} \quad \mathrm{R}^{2}=0.9537, \quad \mathrm{DW}=1.459
\end{array}
$$

If time is also included then we have

$$
\begin{aligned}
& \text { GINI }=1.9749-0.0022(\mathrm{RPCI})+0.8145 \times 10^{-6}(\mathrm{RPCI})^{2} \\
& \mathrm{p} \text {-value (0.000) (0.013) (0.001) } \\
& -0.1013 \times 10^{-9}(\mathrm{RPCI})^{3}+0.0068(\mathrm{TIME}) \quad \mathrm{R}^{2}=0.9729 \\
& \text { (0.002) (0.003) } \quad \mathrm{DW}=2.1354 \\
& \mathrm{JB}=0.94455(0.624)
\end{aligned}
$$

\footnotetext{
${ }^{2]}$ The figure below the regression coefficient is the p-value and not the conventional t-ratio. Smaller pvalue corresponds larger t-ratio.
} 
In both of these equations, $\mathrm{R}^{2}$ is reasonably high and coefficients are significant with lower p-values, and

$$
\left|\beta_{1}\right|>\left|\beta_{2}\right|>\left|\beta_{3}\right|
$$

But, we obtain $\beta_{1}<0, \beta_{2}>0$, and $\beta_{3}<0$, thereby suggesting the existence of the Scurve as an augmented $\mathrm{U}$-curve.

Thus, our results are at variance with those obtained by List and Gallet (1999) and Tribble (1999) in that both of them obtained $\beta_{1}>0, \beta_{2}<0$, and $\beta_{3}>0$. Interestingly, our results compare well with those obtained by Tribble (1999) for lowincome shares and replicated for racial interclass inequality relationships.

If we replace GINI coefficient by PBPL then we get

$$
\begin{array}{lcc}
\text { PBPL }=143.2581-0.0973(\mathrm{RPCI})+0.254 \times 10^{-4}(\mathrm{RPCI})^{2} & \\
\mathrm{p}-\mathrm{value}(0.772) \quad(0.250) & (0.869) & \\
-0.263 \times 10^{-8}(\mathrm{RPCI})^{3}+1.6092(\mathrm{TIME}) & (0.931) & \mathrm{R}^{2}=0.395, \\
(0.914) & \mathrm{DW}=3.47 \\
\mathrm{JB}=0.53108(0.767) &
\end{array}
$$

This result is relatively weaker and p-values are little on higher side but general nature of the relationship is similar to what we get for the GINI coefficient. In view of a high serial correlation we apply Cochrane-Orcutt transformation and get the following equation

$$
\begin{aligned}
& \text { PBPL }=162.026-0.1090(\mathrm{RPCI})+0.2590 \times 10^{-4}(\mathrm{RPCI})^{2} \\
& \text { p-value (0.629) (0.034) (0.784) } \\
& -0.1013 \times 10^{-9}(\mathrm{RPCI})^{3}+0.0068 \text { (TIME) } \\
& \mathrm{R}^{2}=0.7508
\end{aligned}
$$

There is slight improvement in term of values of $\mathrm{R}^{2}$ and $\mathrm{p}$-values, but the extended $\mathrm{U}$ curve hypothesis remains valid. When the time variable is dropped, we get

$$
\begin{aligned}
& \text { PBPL }=342.115-0.359(\mathrm{RPCI})+0.141 \times 10^{-3}(\mathrm{RPCI})^{2} \\
& \mathrm{p} \text {-value (0.486) (0.534) } \\
& -0.184 \times 10^{-7}(\mathrm{RPCI})^{3} \\
& (0.528) \\
& \begin{array}{l}
\mathrm{R}^{2}=0.2318 \\
\mathrm{DW}=2.755>4-\mathrm{d}_{U}
\end{array}
\end{aligned}
$$

$\mathrm{JB}=0.90421(0.636)$

Alternatively, Gini Coefficient as a measure of aggregate inequality based on NSS data has been estimated by Dutt (1996) and available for a longer period 1951-97 in Rao et al. (1999). We get a polynomial of third degree with each of the three coefficients significant at the probability level (p-value) less than even 3 per cent. 


$$
\begin{aligned}
& \text { GINI }(\mathrm{NSS})=90.7663-0.0842(\mathrm{RPCI})+0.3899 \times 10^{-4}(\mathrm{RPCI})^{2} \\
& \text { p-value } \begin{array}{c}
(0.000) \quad(0.000) \\
-0.5891 \times 10^{-8}(\mathrm{RPCI})^{3}
\end{array} \\
& \begin{array}{cc}
(0.000) & (0.000) \\
\mathrm{JB}=0.28229(0.868) & \mathrm{R}^{2}=0.6249 \\
& \mathrm{R}^{2}=0.598 \\
& \mathrm{DW}=1.09
\end{array}
\end{aligned}
$$

Hypothesis of no mis-specification is rejected, as its p-value is $2.60 \%$. However, in none of the above specifications the hypothesis of normality cannot be rejected, as the pvalue in each case is very high. This lends support to the t-values of the regression coefficients $^{1}$ (see Sinha, 2000). The Cochrane - Orcutt method with AR (1) transformation, converged after 4 iterations yielding

$$
\begin{aligned}
& \mathrm{GINI}=76.4808-0.0062926(\mathrm{RPCI})+0.2887 \times 10^{-4}(\mathrm{RPCI})^{2} \\
& \mathrm{p} \text { - value (0.000) (0.023) } \\
& -0.5891 \times 10^{-8}(\mathrm{RPCI})^{3} \\
& \text { (0.030) } \\
& \mathrm{R}^{2}=0.6854 \quad \overline{\mathrm{R}}^{2}=0.6534 \quad \mathrm{DW}=1.9919
\end{aligned}
$$

All the coefficients are again significant at the probability level, which is less than the $3 \%$. Our results support the S-curve (as the augmented U-curve) hypothesis for the period 1951-1998 also as shown in Figure 1. As is evident from the figure the first turning point occurs around 1983 while the second around 1996.

\section{GINI Coefficient and RPCI (1951 - 1998)}

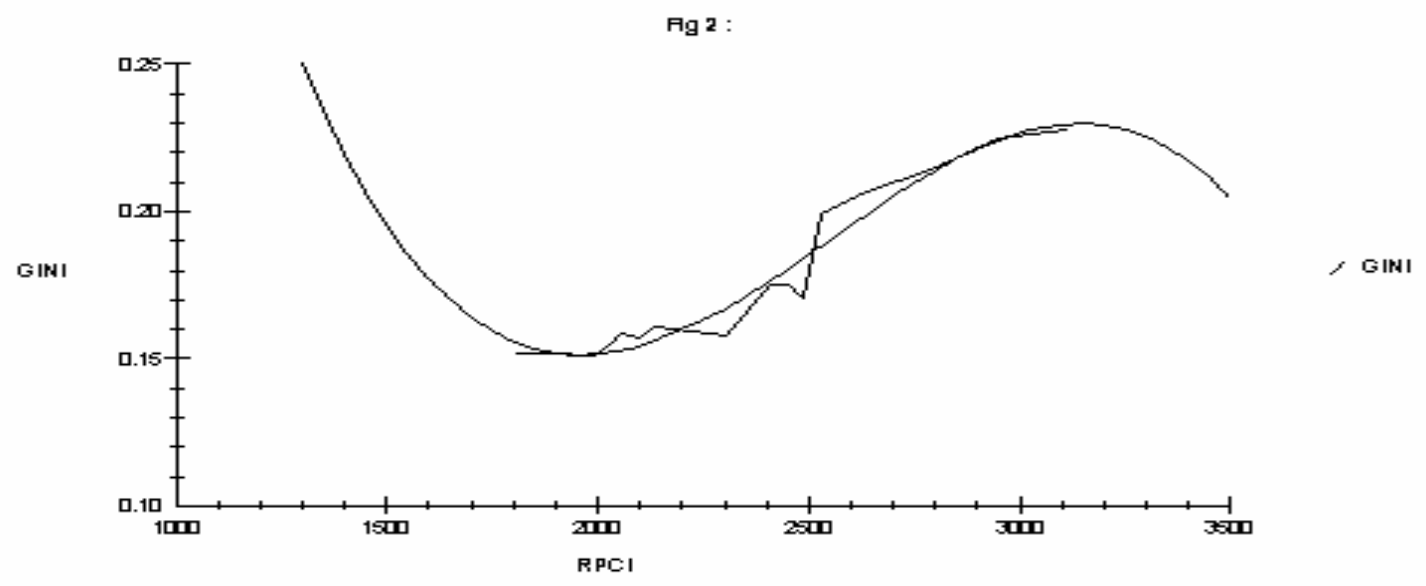

If the inter-state inequality is considered, it starts increasing in 1985 and it declines after the year 1997. Figure 2 presents the relationship between Gini (taken from Ahluwalia, 2000) and RPCI for the period 1981-1998. The S-curve is again endorsed (as an extension of the U-curve). In this case, the first turning point (ATM) occurs around 1985 whereas the second turning point (MTS) is around 1997. In 1998, the Gini coefficient

\footnotetext{
${ }^{1}$ This test has been carried out on the suggestion of Raghbendra Jha of the Australian National University.
} 
has come down to 0.225 from 0.228 in 1997 . The phase of increasing inequality is in fact an evidence of 'trickling-up' effect which appears to have started in 1985 and will eventually be overtaken by another turning point (MTS) in 1997 (the level of RPCI) in 1997 is 3118) and the Gini coefficient is 0.228 . The result obtained here are similar to those in both List et al. and Tribble, but its direction is different in the sense that an Scurve as an extension of the U-curve is obtained.

GINI Coefficient and RPCI (1981 - 1998)

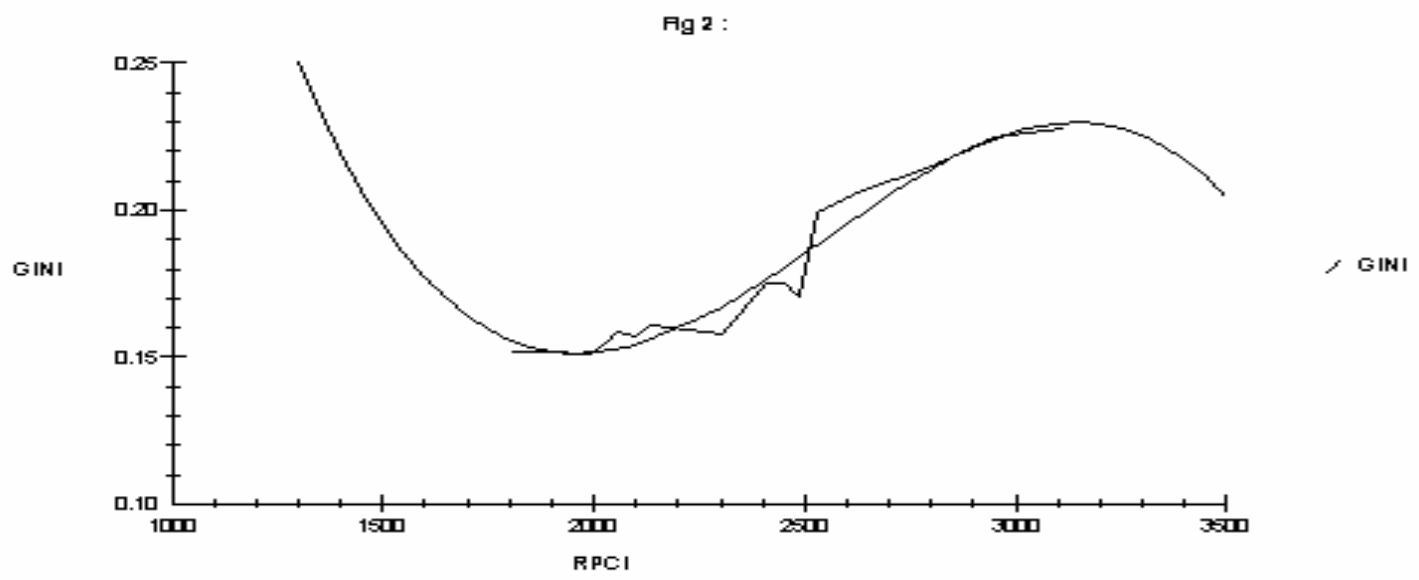

In addition to parabolic and cubic equation, following the suggestion from Tribble, we have estimated quortic and quintic curves also (Table 1). Of these four equations, only the cubic one has all the significant coefficients. (The value of $\mathrm{p}$ does not exceed 1.48 $\%)$. This corroborates the S-curve phenomenon in the growth-inequality relationship.

The results plotted here support the contention that inequality changes with the different phases of the business cycle (Rao et al. 1999). In other words, the first turning point occurred around 1970s, while the second turning point is around (1997-98). If the economic reforms are pursued then the period of decline in the income inequality will follow soon provided political and social restructuring synchronizing the economic restructuring also takes place. Kurian (2000) argues that socio-economic development accentuates the regional disparities. We now need social and political reforms like land reforms, higher investment in education, effective employment schemes, along with economic reforms etc., if inequality is to be reduced.

\section{Summary and Conclusions}

Growing inequality is a universal phenomenon especially among the developed economies; perhaps the US has the highest level of inequality (Gottschalk and Smeeding, 1997). However, the factors responsible for this state differ from country to country. The purpose in this paper is not to investigate the factors affecting the inequality, but to study the relationship between the inequality and per capita income. Various explanations ranging from technology to institutional changes and from market to non-market factors have been suggested to explain this relationship. 
Table 18.1 (1981 to 1998)

\begin{tabular}{|l|c|c|c|c|c|c|c|c|c|}
\hline & Inpt & RPCI & $\mathrm{RPCI}^{2}$ & $\mathrm{RPCI}^{3}$ & $\mathrm{RPCI}^{4}$ & $\mathrm{RPCI}^{5}$ & $\mathrm{R}^{2}$ & $\mathrm{R}^{2}$ & $\mathrm{Degree}^{2}$ \\
\hline Coefficients & -31.3799 & 0.06583 & $-5.42 \mathrm{E}-05$ & $2.2 \mathrm{E}-08$ & $-4.41 \mathrm{E}-12$ & $3.48 \mathrm{E}-16$ & 0.9650 & 0.9492 & - \\
\hline P-value & 0.253254 & 0.255158 & 0.261296 & 0.269954 & 0.28144 & 0.295536 & - & 5 \\
\hline Coefficients & -2.97673 & 0.005852 & $-4.05 \mathrm{E}-06$ & $1.22 \mathrm{E}-09$ & $-1.35 \mathrm{E}-13$ & - & 0.9612 & 0.9483 & - \\
\hline P-value & 0.335142 & 0.264587 & 0.220196 & 0.181761 & 0.152554 & - & - & - & - \\
\hline Coefficients & 1.498322 & -0.001736 & $7.19 \mathrm{E}-07$ & $-9.4 \mathrm{E}-11$ & - & - & 0.9537 & 0.9430 & - \\
\hline P-value & 0.007723 & 0.012373 & 0.012104 & 0.014846 & - & - & - & - & 3 \\
\hline Coefficients & 0.174361 & $-6.38 \mathrm{E}-05$ & $2.7 \mathrm{E}-08$ & - & - & - & 0.925693 & 0.915078 \\
\hline P-value & 0.044646 & 0.353377 & 0.068681 & - & - & - & - & - & 2 \\
\hline
\end{tabular}


Our results contradict the conclusions arrived at by Dutt (1990) that the benefits of economic reforms were limited and the 1990 was a lost decade. On the contrary, the results presented in this paper indicate that economic reforms the country embarked upon in 1991 did result in a turning point due to a shift from manufacturing to service (MTS) resulting from economic restructuring including trade liberalisation and globalisation. The rise in income inequality is mainly because of increasing social inequality as a consequence of political restructuring. Main reason for the increase in inequality is rather institutional, and for this economic reforms cannot be held responsible. The culprit for the increase in inequality lays elsewhere, the policy makers cannot sit-back and look for KHEG to do miracles, Mohan (2000).

Our results conclude that during the period 1980-81 through 1997-98 the Kuznets curve is an S-curve for the Indian economy as well. The paper has examined the two fundamental hypotheses. First, the Gini Coefficient and PBPL follow a random walk, implying thereby that the changes in these indicators are random. Secondly, the relationship between inequality and income is in fact displays S-curve. These results support the performance of economic reforms in India. Any criticism of these reforms based on an increase in inequality may not be empirically valid.

One argument in support of the phenomenon of the increase in the interstate inequality is due to the fact that the rich states are getting rich at a faster rate than the poor states due to factors like globalisation, flowing of foreign investment etc. One of the reasons, associated with the increase in the inequality may be due to growing employment opportunities, associated with uneven earnings growth owing to differences in human capital (for example, technical education). In effect, the earning gap between professionals and technical workers and less skilled workers (especially those in low productivity jobs) widened during the last decade. It may be argued that returns to education have increased faster for better-educated youths. In view of this the economically poor should be provided better access to high-quality education and training in specific skills, if income inequality is to be reduced. Indeed, after the economic reforms the triumph of the market is now widely recognised even where once resisted (like China), but the markets would play a wider and effective role in the development process when an efficient public presence is created and nowhere is it more important than in the realm of income distribution.

Our results partially support Kanbur (1998) and Aghion et al. (1999) who have rightly observed that inequalities have tended to increase in both East Asia and OECD economies. However, the relationship between growth and equity in India has been neither U-shaped nor inverted U-shaped as postulated by Kuznets, but it is S-shaped - an extension of U-curve. The findings of this paper provide a strong support to the contention of the augmented U-curve (leading to an S-curve), for the developing economies. It demonstrates rather significantly the absence of a universal strategy of economic development. 


\section{References:}

Aghion, Philippe; E. Caroli and I. Cecilia Garcia Penalosa, "Inequality and Economic Growth: The Perspective of the New Growth Theories," Journal of Economic Literature, 37: 4, (1999): 1615 - 60.

Ahluwalia, M S, "Economic Performance of States in Post-Reforms Period,” Economic and Political Weekly, May 06-12, 35(19) (2000): 1637-48.

Anand, S and SMR Kanbur, "The Kuznets Process and the Inequality- Development Relationship,” Journal of Development Economics 40(1993): 25 - 52.

Bound J and G Johnson, "Changes in the Structure of Wages in the 1980s: An Evaluation of Alternative Explanations,” American Economic Review, 82 (1992): 371-92.

Bourguinon, Francois, Comment on "Inequality, Poverty and Growth: Where do we stand?” by Albert Fishlow, Annual World Bank Conference on Development Economics, World Bank, Washington D C., (1995).

Dawson, P, “On Testing Kuznets' Economic Growth Hypothesis,” Applied Economic Letters, 4(1997): 409-10.

Dutt, Gaurav, "Poverty in India 1951-1992: Trends and Decomposition,” Draft working paper, January, The World Bank, Washington, DC. (1996).

Dutt, Gaurav, "Has Poverty Declined since Economic Reforms? Statistical Data Analysis," Economic and Political Weekly, December 11 - 17, (1999): 3516-18.

Fishlow, Albert, “Inequality, Poverty and Growth: Where do we stand?” Annual World Bank Conference on Development Economics, World Bank, Washington, 1995.

Gottschalk, P and T Smeeding,"Cross-National Comparisons of Earnings and Income Inequality,” Journal of Economic Literature, 35(2) (1997): 633 - 87.

Greenwood, J and Bajan Jovanovic, "Financial Development, Growth and the Distribution of Income,” Journal of Political Economy, 98(5) (1990): 1076-107.

Jha, Raghabendra, "Growth, Inequality and Poverty in India: Spatial and Temporal Characteristics,” Economic and Political Weekly, March 11 - 17, 2000, 35(11): 921-28.

Kanbur, Ravi, “Income Distribution and Development,” Working Paper 98 - 13, Cornell University, 1998.

Kurian, N J, "Widening Regional Disparities in India: Some Indicators,” Economic and Political Weekly, 35(7) (2000): 538 - 50.

Kuznets, Simon, “Economic Growth and Income Inequality,” American Economic Review, 65 (1955): 1-28.

List, J A and C A Gallet, “The Kuznets Curve: What Happens After the Inverted-U?" Review of Development Economics, 3(2) (1999): 200-06. 
Mohan, T T Ram, "Growth, Poverty and Equity - Red Faces in the World Bank," Economic and Political Weekly, June 24, 35(26) (2000).

Persson, T and Guido Tabellini, “Is Inequality Harmful to Growth?” American Economic Review, 84 (3) (1994): 600 - 21.

Ram, R, “Kuznets’ Inverted-U-Hypothesis: Evidence from Highly Developed Countries,” Southern Economic Journal 57(1991): 1112-23.

Ram, R, "Economic Development and Income Inequality: An Overlooked Regression Constraint,” Economic Development and Cultural Change, 43(1995): 425-32.

Rao, M J, Archana P Samant and Nina Asher, "Indian Macroeconomic Data Base in a Consistency Accounting Framework 1960-61 to 1997-98,” Economic and Political Weekly, 34(Nos. 31 \& 32) (1999):.

Robinson, S A, "Note on the U - Hypothesis Relating Income Inequality and Economic Development," American Economic Review, 66 (1976): 437 - 40.

Sinha, N, "Econometrics of Residuals in Economic Modelling: An Application of Specimetrics to Indian Macro Data," a paper presented at the Seminar on Policy Modelling held at Delhi School of Economics, May 08-09, 2000.

Sinha, N; Sanjeev Kr Jain and Lokendra S Kumawat, "Do Indian Macro Data have a Unit Root?” Mimeo, University of Rajasthan, Jaipur, 2000.

Tribble, (Jr) R, "The Kuznets-Lewis Process within the context of Race and Class in the US Economy,” International Advances in Economic Research, 2 (1996): 151-64.

Tribble, (Jr) R A, "Restatement of the S-curve Hypothesis," Review of Development Economics. 3(2) (1999): 207-14. 
Appendix: Table A1

\begin{tabular}{|c|c|c|c|}
\hline \multirow[t]{2}{*}{ Date } & \multirow[t]{2}{*}{ RPCI } & \multicolumn{2}{|c|}{ GINI Coefficient } \\
\hline & & Aggregate & Inter-state \\
\hline$(1)$ & (2) & $(3)$ & $(4)$ \\
\hline 1951 & 1188 & & \\
\hline 1952 & 1198 & 35.56 & \\
\hline 1953 & 1210 & 35.26 & \\
\hline 1954 & 1260 & 34.62 & \\
\hline 1955 & 1289 & 37.05 & \\
\hline 1956 & 1301 & 35.20 & \\
\hline 1957 & 1347 & 34.17 & \\
\hline 1958 & 1303 & 34.91 & \\
\hline 1959 & 1371 & 34.64 & \\
\hline 1960 & 1372 & 32.59 & \\
\hline 1961 & 1441 & 33.08 & \\
\hline 1962 & 1450 & 32.60 & \\
\hline 1963 & 1446 & 31.79 & \\
\hline 1964 & 1487 & 30.73 & \\
\hline 1965 & 1564 & 31.05 & \\
\hline 1966 & 1471 & 31.14 & \\
\hline 1967 & 1456 & 31.06 & \\
\hline 1968 & 1538 & 30.55 & \\
\hline 1969 & 1543 & 31.86 & \\
\hline 1970 & 1610 & 31.47 & \\
\hline 1971 & 1654 & 30.38 & \\
\hline 1972 & 1630 & 30.79 & \\
\hline 1973 & 1587 & 31.85 & \\
\hline 1974 & 1628 & 30.51 & \\
\hline 1975 & 1617 & 29.17 & \\
\hline 1976 & 1724 & 32.22 & \\
\hline 1977 & 1710 & 32.92 & \\
\hline 1978 & 1797 & 32.14 & \\
\hline 1979 & 1857 & 31.85 & \\
\hline 1980 & 1723 & 32.56 & \\
\hline 1981 & 1808 & 32.10 & 0.152 \\
\hline 1982 & 1878 & 31.74 & 0.152 \\
\hline 1983 & 1883 & 31.67 & 0.152 \\
\hline 1984 & 1990 & 31.49 & 0.151 \\
\hline 1985 & 2020 & 31.69 & 0.154 \\
\hline 1986 & 2058 & 31.84 & 0.159 \\
\hline 1987 & 2095 & 32.22 & 0.157 \\
\hline 1988 & 2134 & 31.82 & 0.161 \\
\hline 1989 & 2301 & 31.15 & 0.158 \\
\hline 1990 & 2410 & 30.46 & 0.175 \\
\hline 1991 & 2485 & 29.69 & 0.171 \\
\hline 1992 & 2449 & 32.53 & 0.175 \\
\hline 1993 & 2528 & 32.02 & 0.199 \\
\hline 1994 & 2636 & 31.71 & 0.207 \\
\hline 1995 & 2791 & 31.06 & 0.214 \\
\hline 1996 & 2945 & 30.33 & 0.225 \\
\hline 1997 & 3118 & 29.25 & 0.228 \\
\hline 1998 & - & 28.73 & 0.225 \\
\hline
\end{tabular}

Sources: Column 2: National Accounts Statistics, EPWRF, Mumbai

Column 3: Rao et al. (1999)

Column 4: Ahluwalia (2000) 
Table A2

\begin{tabular}{|l|l|l|l|l|l|}
\hline \multirow{2}{*}{ States } & \multicolumn{4}{l}{ Growth rate } & \multicolumn{3}{l}{ GINI Coefficient } \\
\cline { 2 - 6 } & $1980-90$ & $1991-97$ & 1957 & 1984 & 1997 \\
\hline$(1)$ & $(2)$ & $(3)$ & $(4)$ & $(5)$ & $(6)$ \\
\hline AP & 5.65 & 5.03 & 32.62 & 30.36 & 30.99 \\
\hline BI & 4.66 & 2.69 & 33.06 & 27.39 & 36.91 \\
\hline GJ & 5.08 & 9.57 & 32.57 & 26.39 & 26.39 \\
\hline HR & 6.43 & 5.02 & & & \\
\hline KR & 5.29 & 5.29 & 36.22 & 31.56 & 28.05 \\
\hline KL & 3.57 & 5.81 & 35.11 & 35.45 & 30.13 \\
\hline MP & 4.56 & 6.17 & 39.56 & 29.81 & 28.41 \\
\hline MH & 6.02 & 8.01 & 30.68 & 30.37 & 32.24 \\
\hline OR & 4.29 & 3.25 & 31.20 & 30.62 & 28.91 \\
\hline PB & 5.32 & 4.71 & 32.67 & 30.11 & 26.19 \\
\hline RJ & 6.60 & 6.54 & 39.08 & 33.55 & 26.45 \\
\hline TN & 5.38 & 6.22 & 34.28 & 33.91 & 26.30 \\
\hline UP & 4.95 & 3.58 & 32.06 & 30.24 & 30.78 \\
\hline WB & 4.71 & 6.91 & 28.35 & 30.43 & 24.48 \\
\hline Total & 5.55 & 6.89 & $34.91 *$ & 31.69 & 28.73 \\
\hline
\end{tabular}

Source: Columns (2) \& (3) Ahluwalia (2000) Table 1, and (4) (5) \& (6) Jha (2000) Table 1. * Rao et al. (1999) 